\title{
Influences of Morphine on the Spontaneous and Evoked Excitatory Postsynaptic Currents in Lateral Amygdala of Rats
}

\author{
Jian-Jun ZHANG ${ }^{1,2}$, Xiao-Dong LIU ${ }^{2}$, Long-Chuan YU ${ }^{2}$ \\ ${ }^{1}$ Key Laboratory of Mental Health, Institute of Psychology, Chinese Academy of Sciences, Beijing, \\ People's Republic of China, ${ }^{2}$ State Key Laboratory of Biomembrane and Membrane Biotechnology \\ and Laboratory of Neurobiology, College of Life Sciences, Peking University, Beijing, People's \\ Republic of China
}

Received March 6, 2015

Accepted July 17, 2015

On-line November 24, 2015

\section{Summary}

Acute morphine exposure induces antinociceptive activity, but the underlying mechanisms in the central nervous system are unclear. Using whole-cell patch clamp recordings, we explore the role of morphine in the modulation of excitatory synaptic transmission in lateral amygdala neurons of rats. The results demonstrate that perfusion of $10 \mu \mathrm{M}$ of morphine to the lateral amygdala inhibits the discharge frequency significantly. We further find that there are no significant influences of morphine on the amplitude of spontaneous excitatory postsynaptic currents (sEPSCs). Interestingly, morphine shows no marked influence on the evoked excitatory postsynaptic currents (eEPSCs) in the lateral amygdala neurons. These results indicate that acute morphine treatment plays an important role in the modulation on the excitatory synaptic transmission in lateral amygdala neurons of rats.

\section{Key words}

Discharge frequency $\bullet$ Excitatory synaptic transmission • Evoked excitatory postsynaptic currents (eEPSCs) • Lateral amygdala • Morphine - Spontaneous excitatory postsynaptic currents (sEPSCs)

\section{Corresponding author}

Long-Chuan Yu, College of Life Sciences, Peking University, Beijing 100871, China. Fax: +86 10 62751526. E-mail: yulc@pku.edu.cn
Acute morphine exposure induced analgesia, while the underlying mechanism might be the rapid neural adaptations and the changes of synaptic transmission (Beckerman et al. 2013, Zheng et al. 2014). The amygdala, a forebrain structure that is positioned to influence pain-modulating circuits (Manning 1998), was involved in morphine analgesia, morphine-induced withdrawal, and morphine-induced conditioned place preference (Calvino et al. 1982, Freedman and Aghajanian 1985, Good and Westbrook 1995, Helmstetter et al. 1993, Lin et al. 2011, Stinus et al. 1990). Previous studies suggested that the glutamatergic and GABAergic transmission in amygdala were affected by acute morphine exposure (Beckerman et al. 2013, Rashvand et al. 2014). The amygdala is anatomically complex, consisting of the central amygdala ( $\mathrm{CeA})$, the basolateral amygdala (BLA) and the lateral amygdala (LA) (McDonald 1998). The BLA (Glass et al. 2005, He et al. 2011, Helmstetter et al. 1995) and CeA (Manning 1998, Manning and Mayer 1995a,b, Rezayof et al. 2011) were postulated to mediate morphine antinociception and rewarding effects, but whether LA plays important roles in acute morphine effects is not clear. Therefore, the present study was carried out to investigate the role of morphine in the modulation of excitatory synaptic transmission in rat LA neurons.

Juvenile Sprague-Dawley rats (P17-P30) were used. Rats were housed under a 12-h light/dark cycle with food and water ad libitum. All procedures were approved 
by the Institutional Animal Care and Use Committee of Peking University.

Brain slices were prepared as described previously (Liu et al. 2011) with minor modifications. Briefly, rats were anesthetized with chloral hydrate $(400 \mathrm{mg} / \mathrm{kg}$, i.p.) and decapitated. The brain was removed into ice-cold high sucrose cutting solution containing (in mM) 90 sucrose, $87 \mathrm{NaCl}, 2.5 \mathrm{KCl}, 1.25 \mathrm{NaH}_{2} \mathrm{PO}_{4}$, $7 \mathrm{MgCl}_{2}, 0.5 \mathrm{CaCl}_{2}, 25 \mathrm{NaHCO}_{3}, 15$ glucose and cooled for $3 \mathrm{~min}$. Then $300-\mu \mathrm{m}$ coronal slices were cut on a vibratome (Leica VT $1000 \mathrm{~S}$, German). Immediately after cutting, slices were stored at $33{ }^{\circ} \mathrm{C}$ for $45 \mathrm{~min}$ in artificial cerebrospinal fluid (ACSF) containing (in $\mathrm{mM}$ ) $125 \mathrm{NaCl}, 2.5 \mathrm{KCl}, 1.25 \mathrm{NaH}_{2} \mathrm{PO}_{4}, 1 \mathrm{MgCl}_{2}, 2 \mathrm{CaCl}_{2}$, $25 \mathrm{NaHCO}_{3}$ and 10 glucose and were equilibrated with $95 \% \mathrm{O}_{2} / 5 \% \mathrm{CO}_{2}$. Whole-cell recordings were done in a chamber superfused with carbogenated ACSF and were performed from visualized neurons located in the LA, with $10 \mu \mathrm{M}$ of bicuculline (Sigma, USA) in the superfusion ACSF to block $\mathrm{GABA}_{\mathrm{A}}$ receptors. Glass microelectrodes (input resistance 2-4 M 2 ) were filled with an internal solution containing (in $\mathrm{mM}$ ):
122.5 Cs-gluconate, 17.5 CsCl, 10 HEPES, 0.5 EGTA, $2 \mathrm{MgCl}_{2}, 4$ ATP, pH 7.2-7.4, osmolarity 300-310 of mOsm. Neurons from LA were recorded using a Heka EPC10 amplifier (Heka, Germany). Synaptic currents were evoked at $0.067 \mathrm{~Hz}$ by stimulation of afferent fibers from the external capsule via a constant-voltage pulse $(1 \mathrm{~ms})$ delivered through a concentric electrode (FHC, USA). After $10 \mathrm{~min}$ baseline recording, according to the previous studies (Nicol et al. 1996, Yang et al. 2004), $10 \mu \mathrm{M}$ of morphine were applied for $15 \mathrm{~min}$. As recovery from responses to morphine could not be obtained with washout up to $15 \mathrm{~min}$ (data not shown), the substance was applied only once to each slice. Morphine was added to the external ACSF.

sEPSCs were detected using Mini-Analysis (Jaejin software, Leonia, NJ, USA). Data from the electrophysiological recordings were analyzed with paired Student's t-test and one-way analysis of variance (ANOVA). Data are presented as mean \pm SEM. Differences were considered statistically significant at $P<0.05$. a

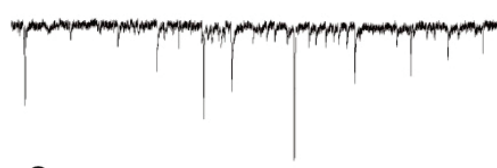

C

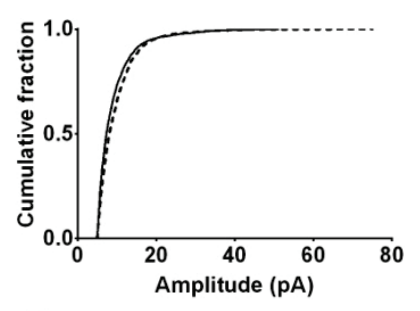

e

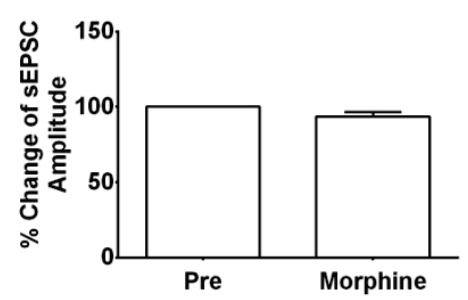

b
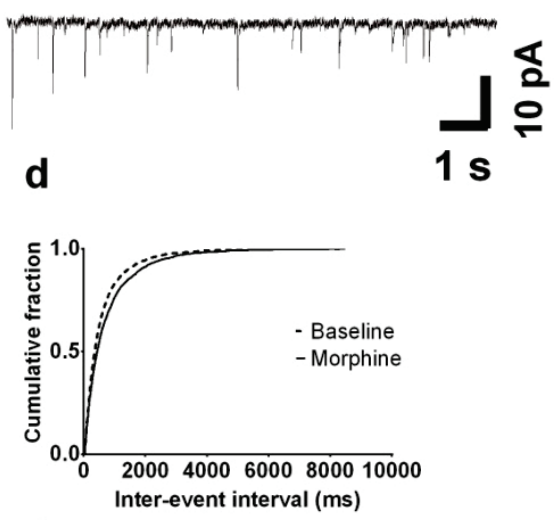

f

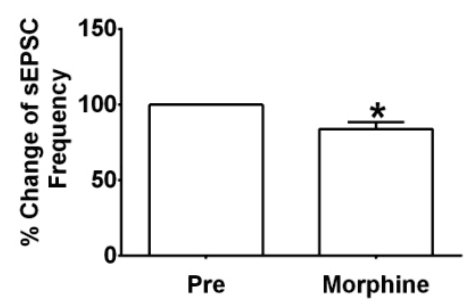

Fig. 1. Acute applying morphine induced decreases in the frequency of SEPSCs, but not amplitude of SEPSCs, of LA neurons in rats. a: Representative traces of sEPSCs from LA neurons under control conditions. b: Representative traces of SEPSCs during the presence of morphine. $\mathbf{c}$ and $\mathbf{d}$ : Morphine $(10 \mu \mathrm{M})$ applied acutely shifted the cumulative inter-event interval of SEPSCs to the right (suggesting a decrease), but it showed no influence on the amplitude of the sEPSCs $(n=7)$. e and $\mathbf{f}$ : Normalized mean values for amplitude and frequency of the sEPSCs showed that the averaged sEPSC frequencies were decreased by acute application of morphine, whereas the averaged amplitudes of SEPSCs were unchanged. Statistical significance $* P<0.05$.
First, we determined the effect of morphine on the activity of 7 LA neurons from 4 rats (Fig. 1). Significant decreases in frequency of spontaneous EPSCs (sEPSCs) were observed upon addition of $10 \mu \mathrm{M}$ morphine, while there were no significant changes in the amplitude after morphine application. Typical current traces under control conditions (Fig. 1a) and during the presence of morphine (Fig. 1b), as well as cumulative amplitude (Fig. 1c) and inter-event interval (Fig. 1d), illustrate the lengthening of inter-event intervals but not 
the amplitude upon addition of morphine. Normalized mean values for amplitude and frequency are shown in Figure 1e and Figure 1f (the last $5 \mathrm{~min}$ of baseline recording and morphine application). Here, the mean amplitude of the sEPSCs changed from $9.3 \pm 0.4 \mathrm{pA}$ in the absence to $8.7 \pm 0.6 \mathrm{pA}$ in the presence of morphine, showed no significant changes (Fig. 1e, $n=7,93.5 \pm 2.9 \%$, $\mathrm{t}=2.106, P>0.05$ ). By contrast, a significant decrease in average frequency of sEPSCs from $1.6 \pm 0.3 \mathrm{~Hz}$ to $1.3 \pm 0.2 \mathrm{~Hz}$ was detected, yielding a decrease to $83.8 \pm 4.8 \%$ (Fig. 1f, $\mathrm{n}=7, \mathrm{t}=2.783, P<0.05$ ).

In the presence of bicuculline $(10 \mu \mathrm{M})$, EPSCs evoked by stimulation of afferent fibers from the external capsule, containing cortical afferents were recorded in 6 LA neuron from 3 rats. Typical current traces under control conditions and during the presence of morphine were shown in Figure 2a. Bath application of morphine $(10 \mu \mathrm{M})$ for $15 \mathrm{~min}$ showed no significant influences on the EPSC amplitude $\left(\mathrm{F}_{19,119}=0.90, P>0.05 ; \mathrm{n}=6\right.$; Fig. $\left.2 \mathrm{~b}\right)$.

\section{a}
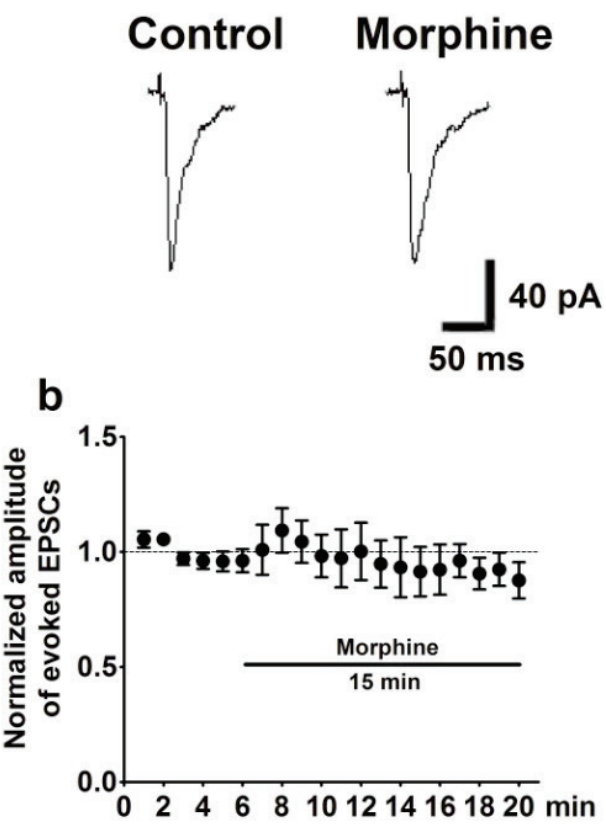

Fig. 2. Morphine showed no significant influences on eEPSCs in neurons of the LA. a: Representative eEPSCs in a LA neuron in control and morphine treatment. $\mathbf{b}$ : Time course of the morphine application on eEPSCs in LA neurons $(n=6)$.

Acute morphine exposure induced analgesia, and studies focus on the pharmacological effect of morphine on the synaptic transmission in the central nervous system were necessary. Testing the sEPSCs and eEPSCs was widely used to study the effects of several drugs on the excitatory synaptic transmission in different brain regions (Akaike et al. 2009, Kato and Shigetomi 2001, Kondratskaya et al. 2010, Kyung Park et al. 2002, Yamamoto et al. 2011). In the present study, morphine perfusion induced marked decreases in the sEPSCs frequency without influences on the amplitude of sEPSCs or EPSC in LA neurons. These results suggest that LA may be one of the earliest brain regions affected by morphine and need more concern. Studies also reported that LA was involved in morphine tolerance (Mitchell et al. 2000), so the present study may be helpful for understanding the effects of LA on morphine tolerance.

It has been reported that $\mu$-opioid receptors (MORs) agonists presynaptically inhibit glutamatergic synaptic transmission in midbrain periaqueductal gray, cultured hippocampal neurons and the centrolateral nucleus (Hashimoto et al. 2009). Consisting with these findings, in the present study, evidence for a presynaptic locus of the morphine-induced inhibition on the glutamate transmission is based on the result that morphine reduced the frequency of sEPSCs, but not amplitude of sEPSCs. The effects of drugs on the sEPSCs were not always consistent with the effects on the eEPSCs. Previous studies found selective activation of presynaptic $\mathrm{GABA}_{\mathrm{A}}$ receptors markedly facilitated sEPSCs frequency but inhibited eEPSCs amplitude (Yamamoto et al. 2011), and ATP significantly reduced the amplitude of eEPSCs but increased the frequency of sEPSCs (Kato and Shigetomi 2001). Because LA receives a great deal of inputs (Buffalari and See 2010), sEPSCs represent the sum of all the postsynaptic currents. In this study, synaptic currents were evoked by stimulation of afferent fibers from the external capsule, so eEPSCs only reflect part of the afferent projection. The frequency of sEPSCs might also reflect the number of excitatory synapses of the recorded neurons (Wang and Zheng 2001).

Glutamatergic inputs onto the LA primarily arise from sensory association cortices, prelimbic cortex, hippocampus and thalamus (Doron and Ledoux 2000, Kishi et al. 2006, McDonald 1998), which allows the LA to integrate information involving sensory inputs and past experiences. The present results suggest that morphine may inhibit glutamate release presynaptically in LA, while the neuronal circuit underlying the inhibition of morphine on the glutamatergic release remains to be determined.

In conclusion, the present study demonstrate that morphine inhibits the frequency of sEPSCs, but not the amplitude of sEPSCs, in the LA neurons. The results may provide a cellular basis for the function of LA in acute 
morphine induced analgesia.

\section{Conflict of Interest}

There is no conflict of interest.

\section{Acknowledgements}

The study was supported by funds from the National
Natural Science Research Foundation of China (NSFC: 30711120564, 31400880), National Program of Basic Research sponsored by the Ministry of Science and Technology of China (2009CB522002), and Key Laboratory of Mental Health, Institute of Psychology, Chinese Academy of Sciences (KLMH2014ZG02).

\section{References}

AKAIKE H, SHIN MC, KUBO C, AKAIKE N: Effects of scorpion toxin on excitatory and inhibitory presynaptic terminals. Toxicology 264: 198-204, 2009.

BECKERMAN MA, OGORODNIK E, GLASS MJ: Acute morphine associated alterations in the subcellular location of the AMPA-GluR1 receptor subunit in dendrites of neurons in the mouse central nucleus of the amygdala: comparisons and contrasts with other glutamate receptor subunits. Synapse 67: 692-704, 2013.

BUFFALARI DM, SEE RE: Amygdala mechanisms of Pavlovian psychostimulant conditioning and relapse. Curr Top Behav Neurosci 3: 73-99, 2010.

CALVINO B, LEVESQUE G, BESSON JM: Possible involvement of the amygdaloid complex in morphine analgesia as studied by electrolytic lesions in rats. Brain Res 233: 221-226, 1982.

DORON NN, LEDOUX JE: Cells in the posterior thalamus project to both amygdala and temporal cortex: a quantitative retrograde double-labeling study in the rat. J Comp Neurol 425: 257-274, 2000.

FREEDMAN JE, AGHAJANIAN GK: Opiate and alpha 2-adrenoceptor responses of rat amygdaloid neurons: co-localization and interactions during withdrawal. J Neurosci 5: 3016-3024, 1985.

GLASS MJ, KRUZICH PJ, COLAGO EE, KREEK MJ, PICKEL VM: Increased AMPA GluR1 receptor subunit labeling on the plasma membrane of dendrites in the basolateral amygdala of rats self-administering morphine. Synapse 58: 1-12, 2005.

GOOD AJ, WESTBROOK RF: Effects of a microinjection of morphine into the amygdala on the acquisition and expression of conditioned fear and hypoalgesia in rats. Behav Neurosci 109: 631-641, 1995.

HASHIMOTO K, AMANO T, SAKAI N, SUZUKI T, NARITA M: Cell-dependent physiological synaptic action of morphine in the rat habenular nucleus: morphine both inhibits and facilitates excitatory synaptic transmission. Neurosci Lett 451: 270-273, 2009.

HE YY, XUE YX, WANG JS, FANG Q, LIU JF, XUE LF, LU L: PKMzeta maintains drug reward and aversion memory in the basolateral amygdala and extinction memory in the infralimbic cortex. Neuropsychopharmacology 36: 1972-1981, 2011.

HELMSTETTER FJ, BELLGOWAN PS, POORE LH: Microinfusion of mu but not delta or kappa opioid agonists into the basolateral amygdala results in inhibition of the tail flick reflex in pentobarbital-anesthetized rats. J Pharmacol Exp Ther 275: 381-388, 1995.

HELMSTETTER FJ, BELLGOWAN PS, TERSHNER SA: Inhibition of the tail flick reflex following microinjection of morphine into the amygdala. Neuroreport 4: 471-474, 1993.

KATO F, SHIGETOMI E: Distinct modulation of evoked and spontaneous EPSCs by purinoceptors in the nucleus tractus solitarii of the rat. J Physiol 530: 469-486, 2001.

KISHI T, TSUMORI T, YOKOTA S, YASUI Y: Topographical projection from the hippocampal formation to the amygdala: a combined anterograde and retrograde tracing study in the rat. J Comp Neurol 496: 349-368, 2006.

KONDRATSKAYA E, SHIN MC, AKAIKE N: Neuronal glutamate transporters regulate synaptic transmission in single synapses on CA1 hippocampal neurons. Brain Res Bull 81: 53-60, 2010.

KYUNG PARK Y, JUN JUNG S, KWAK J, KIM J: Effect of hypoxia on excitatory transmission in the rat substantia gelatinosa neurons. Biochem Biophys Res Commun 295: 929-936, 2002.

LIN X, WANG Q, CHENG Y, JI J, YU LC: Changes of protein expression profiles in the amygdala during the process of morphine-induced conditioned place preference in rats. Behav Brain Res 221: 197-206, 2011. 
LIU XD, ZHANG JJ, WANG Y, YU LC: Inhibitory effects of calcitonin gene-related peptide on long-term potentiation induced in hippocampal slices of rats. Neurosci Lett 494: 10-13, 2011.

MANNING BH: A lateralized deficit in morphine antinociception after unilateral inactivation of the central amygdala. J Neurosci 18: 9453-9470, 1998.

MANNING BH, MAYER DJ: The central nucleus of the amygdala contributes to the production of morphine antinociception in the formalin test. Pain 63: 141-152, 1995a.

MANNING BH, MAYER DJ: The central nucleus of the amygdala contributes to the production of morphine antinociception in the rat tail-flick test. $J$ Neurosci 15: 8199-8213, 1995 b.

MCDONALD AJ: Cortical pathways to the mammalian amygdala. Prog Neurobiol 55: 257-332, 1998.

MITCHELL JM, BASBAUM AI, FIELDS HL: A locus and mechanism of action for associative morphine tolerance. Nat Neurosci 3: 47-53, 2000.

NICOL B, ROWBOTHAM DJ, LAMBERT DG: mu- and kappa-opioids inhibit $\mathrm{K}+$ evoked glutamate release from rat cerebrocortical slices. Neurosci Lett 218: 79-82, 1996.

RASHVAND M, KHAJAVAI A, PARVIZ M, HASANEIN P, KESHAVARZ M: GABAA receptors are involved in the analgesic effects of morphine microinjected into the central nucleus of the amygdala. Clin Exp Pharmacol Physiol 41: 338-344, 2014.

REZAYOF A, SARDARI M, ZARRINDAST MR, NAYER-NOURI T: Functional interaction between morphine and central amygdala cannabinoid CB1 receptors in the acquisition and expression of conditioned place preference. Behav Brain Res 220: 1-8, 2011.

STINUS L, LE MOAL M, KOOB GF: Nucleus accumbens and amygdala are possible substrates for the aversive stimulus effects of opiate withdrawal. Neuroscience 37: 767-773, 1990.

WANG Z, ZHENG P: Characterization of spontaneous excitatory synaptic currents in pyramidal cells of rat prelimbic cortex. Brain Res 901: 303-313, 2001.

YAMAMOTO S, YOSHIMURA M, SHIN MC, WAKITA M, NONAKA K, AKAIKE N: GABA(A) receptormediated presynaptic inhibition on glutamatergic transmission. Brain Res Bull 84: 22-30, 2011.

YANG TT, HUNG CF, LEE YJ, SU MJ, WANG SJ: Morphine inhibits glutamate exocytosis from rat cerebral cortex nerve terminals (synaptosomes) by reducing Ca2+ influx. Synapse 51: 83-90, 2004.

ZHENG Q, LIU Z, WEI C, HAN J, LIU Y, ZHANG X, REN W: Activation of the D1 receptors inhibits the long-term potentiation in vivo induced by acute morphine administration through a D1-GluN2A interaction in the nucleus accumbens. Neuroreport 25: 1191-1197, 2014. 